\section{CARMEN DE BURGOS Y LAS COLECCIONES DE NOVELA CORTA}

\author{
Alberto Sánchez Álvarez-Insúa
}

Instituto de Filosofía CSIC

\begin{abstract}
The article studie the literary production of Carmen de Burgos to the form the short novels. The literary collections and the tematic are related.
\end{abstract}

KEY WORDS: Short novels of Colombine; literary collections.

En el año 1907 se inicia en España un fenómeno literario sin precedentes: la aparición de un conjunto ingente de colecciones literarias (Sánchez, 1996 y 2001). El pistoletazo de salida corre a cargo de Eduardo Zamacois, con la creación de la colección El Cuento Semanal (Magnien, 1986). Los avatares que tuvieron lugar son bien conocidos: Zamacois visitó a un buen número de editores y la respuesta fue siempre la misma: "los autores españoles no venden". Efectivamente, colecciones anteriores a El Cuento Semanal hubo varias: algunas colecciones de libros de pequeño formato y otras como La Novela llustrada (1884) que sería dirigida en una de sus etapas por Vicente Blasco Ibáñez. Su producción sería en su totalidad extranjera: Maupassant, Hugo, Dumas, Dickens, los hermanos Goncourt, Dostoiewsky, Turgueniev, las novelas históricas de Conan Doyle y los primeros Raffles de Hornung. Tuvo una periodicidad semanal, tenía casi cien páginas y costaba 35 cts. Publicó más de trescientos títulos. De igual tenor fue La Novela de Ahora surgida también en 1907 y editada por Saturnino Calleja. Tuvo tres épocas. En la primera, y bajo el lema Literatura-Arte-Moralidad-Amenidad-Cultura, alternó el folletín con la novela de aventuras: Salgari, Feval y Ponson du Terrail. En su etapa final, y sin duda por la vía iniciada por El Cuento Semanal publicó obras de autores españoles: Palacio Valdés, Cánovas, Frontaura, Ortega y Frías, Navarro Villaoslada y Selgas. Tenía también del orden de las cien páginas y costaba 30 cts. Publicó alrededor de doscientos cincuenta títulos. Finalizamos este recorrido previo señalando que hubo colecciones como La Novela Maestra editada en Barcelona por El Gato Negro, de autor

\section{CARMEN DE BURGOS AND THE SHORT NOVEL COLLECTIONS}

RESUMEN: Se estudia la producción literaria de Carmen de Burgos en forma de novela corta. Se dan noticias de las diferentes colecciones y de los contenidos de las novelas.

PALABRAS CLAVE: Novelas cortas de Colombine; colecciones literarias.

único, en este caso, Alejandro Dumas. Tenía tamaño tabloide y costaba 65 cts.

Aunque Zamacois insistió muy mucho en el carácter profundamente español de su colección y señaló como fuente de inspiración La Vida Galante, semanario que él dirigía y que redactaba en su casi totalidad, la verdad es muy otra: se inspiró en los suplementos literarios de algunas revistas francesas como L'lllustration y La Petite Illustration. Zamacois, a caballo entre Madrid, Barcelona y París, conocía muy bien el panorama literario de las tres capitales.

El número que da inicio a El Cuento Semanal es Desencanto de Jacinto Octavio Picón. Queda muy clara en esta elección que la tónica general de la serie va a ser el naturalismo. Zamacois combinó, con gran habilidad, autores consagrados con noveles prometedores como HernándezCatá, Insúa o Colombine. Un concurso da el premio de novela corta a Gabriel Miró, por su opera prima, Nómada.

También son bien conocidas las circunstancias en que Zamacois pierde la cabecera de El Cuento Semanal. Suicidio de su socio, querella de su viuda que reclama la dirección y propiedad de la serie y juicio rápido que le da la razón. Como respuesta, Zamacois funda en 1909 una colección paralela, Los Contemporáneos, que sería la que alcanzó el mayor número de títulos de todas ellas (Sánchez, 2007). Algunos aspectos de ambas creemos necesario señalar: 
- Tanto una como otra siguen, en los aspectos formales, el modelo de las revistas finiseculares: $250 \times 150 \mathrm{~mm}$., 24 páginas, papel couché, ilustraciones con fotograbado en blanco y negro y color integradas en el texto, doble coIumna. Tuvieron periodicidad semanal y costaban 30 cts. El Cuento Semanal (1907-1912) alcanzó los 263 títulos, y Los Contemporáneos (1909-1926), 898.

- Desde su inicio hay una notable identificación entre textos y receptores. Los españoles estaban esperando que escritores compatriotas les mostraran como era España y los españoles y como debería ser. Se había salido del duro proceso del 98 y el vacío de señas de identidad era notable. Así, cada novela, cada artículo, cada obra de teatro o cada poema respondían a un discurso identitario narrativo, de forma más o menos inconsciente. Aunque existieron series de novelas de autores extranjeros, la demanda se centra en autores españoles. Es más, cuando El Cuento Semanal, falto de originales, publica obras de escritores notables como Eça de Queiroz o Twain, excelentemente traducidos, el público protesta. De hecho, la falta de originales españoles supuso el fin de alguna colección como $L a$ Novela Semanal.

- En estas colecciones, y en otras, tiene lugar una feliz conjunción entre la pluma y el lápiz. Al texto acompañan siempre ilustraciones litográficas que pasan a ser de dibujo de línea cuando cambian, como ya veremos, cuando la escasez de papel, promovida por la I Guerra Mundial elimina el couché y se pasa a utilizar papel prensa de baja calidad.

- El movimiento creado por El Cuento Semanal dará lugar a múltiples colecciones de todo orden. Madrid y Barcelona serán los centros editoriales de mayor importancia, pero también aparecerán otros como Valencia, Sevilla, Zaragoza, e incluso pueblos como Puente Genil.

- Pronto las colecciones adquirirán caracteres diferenciados apareciendo series de novela corta, teatro, poesía, novelas eróticas, novelas de inspiración política, novelizaciones de películas mudas, de sucesos luctuosos, series biográficas, etc. La producción estimada es de unos cien mil títulos.

- La demanda supera con mucho a la oferta. Esto da lugar a dos fenómenos: la aparición de colecciones literarias no novelísticas que a pesar de publicar teatro siguen utilizando el término novela, como La Novela Cómica y La Novela Teatral; y la omnipresencia del "refrito", término que algunos no acaban de comprender y que supone publicar más de una vez la misma novela cambiando de título. Del refrito fue Emilio Carrere el monarca supremo.

- Las tiradas se harán inmensas, algunas desmesuradas e impensables en estas fechas. Del primer número de $L a$ Novela Corta, Sor Simona de Pérez Galdós Ilegaron a tirarse doscientos cincuenta mil ejemplares. Esto posibilitó un abaratamiento notable, entre 5 y 10 cts. La lectura se convierte así en la forma más barata de ocio. En el caso citado de La Novela Corta sus últimos números sólo alcanzaron la tirada de cincuenta mil ejemplares, lo que se consideró un fracaso económico y dio fin a la colección.

- La competencia entre colecciones es notable, y algunos autores abandonan la precedente y se alinean con el mejor postor. Esto sucedió entre La Novela Semanal, publicada por Prensa Gráfica que, pese a la potencia de su holding editorial, se vio desplazada por La Novela de Hoy, dirigida por Artemio Precioso.

Aunque El Cuento Semanal y Los Contemporáneos son las dos colecciones iniciales representativas pronto tendrá lugar un doble fenómeno: la reducción de formato hasta alcanzar el de bolsillo con dos colecciones de transición: El Libro Popular (1912-1914) que alcanzó los 104 títulos y redujo el formato a $210 \times 150 \mathrm{~mm}$., y el precio a 20 cts., manteniendo el couché y las litografías; y La Novela de Bolsillo (1914-1916) que, como su propio nombre indica, tenía un formato reducido $137 \times 82 \mathrm{~mm}$., costaba 30 cts., y alcanzó los cien números. Las circunstancias de las fechas de su publicación la obligaron a cambiar de papel, utilizando en sus cincuenta últimos números papel prensa barato, en lugar del couché inicial. Esto obligó a sustituir el huecograbado por el dibujo de línea (Sánchez, 1997).

Pero la gran colección, la que mostró a los lectores todo el panorama literario español, ya que la práctica totalidad de los autores publican en ella, fue La Novela Corta (1916-1925) (Mogin, 2000) que emprende su cruzada de la mano de José de Urquía. El precio se reduce a 5 cts., aunque enseguida sube a 10, y el papel es de ínfima calidad así como la impresión. Si en El Cuento Semanal y Los Contemporáneos la iconografía de las portadas es la caricatura de los autores, en general a cargo de Manolo Tovar, La Novela Corta instaura la fotografía silueteada de los escritores, aunque en su etapa final utiliza el dibujo en cuatricromía. Su extensión era de un pliego de 36, portadas incluidas, aunque algunos extras tuvieron el doble de 
páginas. Alcanzó los 499 títulos, de los cuales sólo uno era de un autor extranjero: La isla de los pingüinos de Anatole France, traducida y extractada por Ruiz Contreras. Este tipo de extractos a cargo de sus propios autores, anticipándose en muchos años al Reader's Digest norteamericano, se dio con mucha frecuencia en La Novela Corta: Azorín, Trigo, e Insúa, entre otros, convirtieron novelas largas en cortas. Publicó también la colección excelentes estudios literarios de autores sobresalientes: Trigo, Pardo Bazán, Alarcón, etc.; otros denominados "Las mujeres de..." (Belda, Retana, Benavente, etc.), y hasta estudios "bíblicos". Ante una demanda creciente, la editorial lanza, con el mismo formato, La Novela Teatral (1916-1925) (Pérez, 1996) con 447 títulos, a la que adelantó la Novela Cómica (19161919) (García-Abad, 1997) con 183 títulos. Ambas son, claro está, colecciones teatrales que recuperan la tradición decimonónica del "teatro para leer".

Dentro del panorama general de la novela corta aparecerán cientos de colecciones, algunas que apuntaban directamente al receptor y en que protagonistas y lectores se identifican: La Novela de la Modistilla, La Novela del Chófer, La Novela Deportiva, y hasta las mujeres de vida airada tuvieron su colección: Biblioteca Moderna. Cómo viven las mujeres. Estudios de la vida íntima de las mujeres de mundo durante las veinticuatro horas del día (Barcelona, s.a.). Otras fueron de lo más pintoresco: El Cuento de la Suerte, que incluía el listado de los premios de la lotería o la colección Los Noveles, que únicamente admitía obras de autores no conocidos y operas primas.

La producción en lenguas vernáculas también tuvo lugar, sobre todo en Cataluña: La Novela Nova, La Novel.Ia D'Ara, La Novel.la Teatral Catalana y La Escena Catalana; y en Valencia: El Cuento del Dumenche y Teatro Valenciá. La producción de literatura burguesa se hizo en las lenguas vernáculas, mientras que la proletaria, como la anarquista publicada por La Revista Blanca y Tierra y Libertad: La Novela Ideal (Siguán, 1981) y La Novela Libre, se editaron en castellano.

Dos líneas de publicación tuvieron las series de novela corta: las de inspiración política, entre las que destacaron las catalanas ya citadas junto con La Novela Proletaria (1932-1933) (Santonja, 1979), las dos series de La Novela Roja (junio-julio 1931, dirigida por Ceferino Rodríguez Avecilla) y La Novela Roja (1922-1923, dirigida por
Fernando Pintado) (Santonja, 1994) y La Novela Política. Dentro de ellas cabe citar dos colecciones que desde un punto de vista ideológico habría que considerar incerte sedis: La Novela Gráfica y Los 13, dirigida por El Caballero Audaz. Durante la guerra civil se publicaron nuevas series: La Novela del Miliciano (Bilbao, Sindicato Único de Artes Gráficas CNT), Los Hombres del Pueblo (Madrid, 1937), La Semana Literaria Populary Vidas revolucionarias (Valencia, 1937, Editorial Guerri colectivizada), y dentro del bando "nacional" La Novela del Sábado (Sevilla-Madrid, 1939) que se inaugura con una obra de Francisco Franco, Marruecos. Diario de una bandera, ya publicada con prólogo de Millán Astray cuando el futuro dictador era comandante de la primera bandera de la Legión; La Novela de Vértice (1938-1941) (Naval, 2000), suplemento literario de la revista falangista del mismo título, que ve la luz unos días después del Decreto de Unificación, y Los Novelistas (San Sebastián-Barcelona, dirigida por José Simón Valdivieso). Otra colección, Biblioteca Rocío evolucionó de novela de guerra a novela rosa.

La segunda línea de publicación fueron las novelas eróticas que conocieron todas las gradaciones, desde lo picaresco a lo claramente pornográfico. Hay unas diferencias notables entre las series madrileñas, cuyo paradigma sería La Novela Pasional (Madrid, 1924-1928), y las de Barcelona como La Novela Deliciosa (1931-1933) o La Novela Inocente, de las mismas fechas (Sánchez, 2007). Siguiendo la costumbre francesa de los editores de pornografía algunas series falsearon el lugar de edición eligiendo París, Tarbes e incluso Buenos Aires.

Señalar, finalmente que se publicaron numerosa series de novelizaciones de películas, de obras teatrales, de poesía, de sucesos y biográficas.

\section{La obra corta de Carmen de Burgos, Colombine}

Dos años antes de la aparición de El Cuento Semanal, Carmen de Burgos hace sus primeras armas en una colección de pequeño formato, Biblioteca Mignon (1905), con varios cuentos: Alucinación, El fiscal, Sacrificio, entre otros, volumen 42 (1905). Pero su auténtico despegue como autora de novelas cortas será precisamente en las dos colecciones dirigidas por Eduardo Zamacois. En El Cuento Semanal publicó

ARBOR CLXXXVI EXTRA JUNIO 2010 65-70 ISSN: 0210-1963 
cuatro entregas cuyos números y fechas se señalan: 25.- El tesoro del castillo (21-6-1907); 81.- Senderos de vida (177-1908); 148.- En la guerra (29-10-1909); 238.- El honor de la familia (21-7-1911). En Los Contemporáneos diez y siete títulos más: 57.- El veneno del arte (1910); 172.- Siempre en tierra (1912); 340.- El abogado (1915); 371.- Los usureros (1916); 388.- Ellas y Ellos o Ellos y Ellas (1916); 416.- Don Manolito (1916); 437.- El permisionario (1916); 459.- El desconocido (1917); 518.- Los inadaptados (1918); 559.- El fin de la guerra (1919); 623.- Confidencias (1920); 655.- La rampa (1921); 671.- Los anticuarios (1921); 689.- El último contrabandista (1922); 708.- La prueba (1922); 724.- Los huesos del abuelo (1922); y 772.- La tornadiza (1923).

Esta colaboración con las dos grandes colecciones no entraña que se olvidara de otras, aunque su participación fue menor. En El Libro Popular (1912-1914) colección dirigida por Antonio Lezama y por Gómez Hidalgo (Correa, 2001), publicó cuatro novelas: 10.- La indecisa (12-9-1912); 24.La justicia del mar (19-12-1912); 90.- Malos amores (173-1914) y 105.- Frasca la Tonta (30-6-1914); mientras que en La Novela de Bolsillo (1914-1916) que alcanzó los 100 títulos sólo publicó una: 8.- Sorpresas (1914).

Pero la colección que conoció una mayor participación de Colombine desde sus inicios hasta su final fue La Novela Corta (1916-1925) con veintitrés entregas: 27.- El hombre negro (8-7-1916); 59.- El perseguidor (17-2-1917); 81.- Pasiones (27-7-1917); 137.- Venganza (17-8-1918); 155.- La mejor film (21-12-1918); 180.- Dos amores (14-6-1919); 195.- Las negociaciones de la Puerta del Sol (27-9-1919); 231.- La flor de la playa (29-5-1920); 243.- La emperatriz Eugenia, su vida (1-8-1920); 254.- Los amores de Faustino (30-10-1920); 292.- La entrometida (16-7-1921); 310.- La ciudad encantada (12-11-1921); 328.- La mujer fría (253-1922); 339.- El suicida asesinado (3-6-1922); 356.- La princesa rusa (30-9-1922); 371.- La pensión ideal (13-11923); 384.- La que se casó muy niña (14-4-1923); 398.La mujer fantástica (21-7-1923); 410.- El hastío del amor (13-10-1923); 422.- Hasta renacer (5-1-1924); 438.- Las ensaladillas (28-4-1924); 457.- La miniatura (6-9-1924); y 491.- El brote (18-4-1925).

Dentro de algunas colecciones de menor número de títulos Colombine participó también en La Novela con Regalo (Valencia, 1916-1917, el "regalo eran las tapas para encuadernar la serie) con dos entregas; 5.- Lo inesperado
(1916) y 4 (año 2).- Una bomba (1917); y en La Novela para Todos (Madrid, 1916) con una: 17.- Los miseros (1916). En la curiosa colección ya citada La Novela Gráfica (Madrid, 1922) dirigida por un enigmático director-propietario $\mathrm{Ma}$ quiavelo, seudónimo de imposible identificación publicó otra: 20.- La herencia de la bruja (1923).

De nuevo dos grandes colecciones reclaman su participación: La Novela Semanal publicada por Prensa Gráfica entre 1921 y 1925, que alcanzó los 233 títulos (Fernández, 2001) publicó cinco entregas: 15.- El artículo 438 (110-1921); 94.- El extranjero (28-4-1923); 106.- El anhelo (21-7-1923); 193.- La melena de la discordia (21-3-1925) y 222.- La nostálgica (10-10-1925). Pese a que La Semanal entra en una dura competencia con La Novela de Hoy (1922-1932, 525+1 títulos) (Labrador, 2005), pues Artemio Precioso, su director, paga espléndidamente, Colombine la acompañó fielmente, como ya hiciera en La Novela Corta, hasta su final. Tardará en incorporarse a la colección de Precioso, y lo hará a partir de 1929 con nueve entregas: Precioso, gran amigo de Santiago Alba, tuvo que exiliarse por la persecución a que le sometió el Dictador, siendo sustituido por Pedro Sainz Rodríguez que se hizo cargo de todo, incluso de las publicaciones subidas de tono. Carmen de Burgos firmó nueve entregas: 352.- Se quedó sin ella (8-2-1929); 404.- El dorado trópico (7-2-1930); 417.- iLa piscina! iLa piscina! (9-5-1930); 450.- Vida y milagros del pícaro Andresillo Pérez (26-12-1930 número almanaque); 478.- La ironía de la vida (10-7-1931); 487.- Perdónanos nuestras deudas (11-9-1931); 495.- Puñal de claveles (13.11-1931); 510.- Guiones del destino (4-3-1932); 518.Cuando la ley lo manda (28-4-1932).

Colombine también participó en dos colecciones "pasionales": La Novela de Noche (1924-1926), editada también por Artemio Precioso, que publicó 61 títulos (Labrador, 2005), con una sola entrega: 58.- La confidente (15-8-1926) y La Novela Pasional (1924-1928) que editó 186 volúmenes, con otra: 84.- La que quiso ser maja (1924?). Algunos volúmenes de La Pasional, y entre ellos el que nos ocupa, han sido reeditados por la editorial Renacimiento de Sevilla.

En 1926 Carmen de Burgos publica sus últimas aportaciones a la novela corta: en La Novela Femenina (1926), dos títulos: 3.- La prueba (1926) y 20.- El silencio del hijo; y en La Novela Mundial (1926-1928) dirigida por García Mercadal, que alcanzó los 130 números (Sánchez y San- 
tamaria, 1997), otros dos: 21.- Misionera en Teotihuacan (5-8-1926) y 73.- El "Misericordia" (4-8-1927). Todavía podemos reseñar dos títulos más aparecidos en formato bolsillo pero sin pertenecer a una colección determinada: Prensa Gráfica (1930) S.N.- El novenario (1930) y La Novela Romántica (S. A.), S.N.- Las tricanas. En 1932 publicó una de sus obras, 207.-Los endemoniados de Jaca (18 de diciembre de 1932) en Novelas y Cuentos, en sus tres épocas, antes y después de la guerra, alcanzó 1999 títulos.

\section{LA temática de las nOVelas cortas de Colombine}

El tema central de la obra narrativa corta de Carmen de Burgos es el amor: amores imposibles, El novenario, fracasados, Siempre en tierra, La indecisa, Sorpresa, La flor de la playa, Confidencias, Una mujer fría, El hastío del amor, La tornadiza, Las ensaladillas, Se quedó sin ella, El anhelo, Los endemoniados de Jaca, felices, Dos amores, La ciudad encantada, La prueba, El brote, Perdónanos nuestras deudas, Puñal de claveles, Cuando la ley lo manda, trágicos con historia trágica, El "Misericordia", El dorado trópico, Guiones del destino, los amores culpables, el crimen y los celos, La justicia del mar, Malos amores, iTodos menos ese!, Los inadaptados, El artículo 438 (la ley que permitía el asesinato de la adúltera), los amores no realizados y la soledad, En la guerra, el matrimonio que puede desde ser un tesoro a la tumba del amor: El amor es un tesoro, El hombre negro, Luna de miel, La que se casó muy niña.

Además del amor, la guerra, la Gran Guerra, fue otro tema central de Colombine, El permisionario, Pasiones, El desconocido, El fin de la guerra. 0 el arte, El veneno del arte, La mejor film. 0 aspectos problemáticos como la homosexualidad masculina y femenina, Ella y ellos y ellos y ellas o la drogadicción, Hasta renacer, la crítica político social, El honor de la familia, Frasca la tonta, la usura y la corrupción, Los usureros, El abogado, Los negociantes de la Puerta del Sol, la falsedad, el engaño, la búsqueda de la felicidad, la maternidad en la soltería y los hijos producto de relaciones culpables. Los temas se harían interminables. Cultivó Carmen de Burgos la novela de género: policiaco, El suicida asesinado, fantástico, La herencia de la bruja, la novela picaresca, Vida y milagros del pícaro Andresillo Pérez. Cultivó también el género biográfico: Teresa (los amores de Teresa y Espronceda) y La emperatriz Eugenia, su vida. Finalizar señalando que una de las localizaciones que utiliza Colombine son los hoteles: Villa María, La pensión Ideal.

Aunque el refrito fue moneda de uso corriente, Carmen de Burgos sólo publicó dos veces la misma novela breve: Frasca la tonta o Venganza y La prueba (en Los Contemporáneos y La Novela Femenina). De la misma manera sólo extractó dos de sus novelas grandes: Los anticuarios y El último contrabandista.
Recibido: 14 de mayo de 2010

Aceptado: 7 de junio de 2010

\section{BIBLIOGRAFÍA}

Correa, Amelina (2001): El Libro Popular, Madrid, CSIC, Literatura Breve 7.

Fernández Gutiérrez, José María (2001): La Novela Semanal, Madrid, CSIC, Literatura Breve 5.

García-Abad, M. ${ }^{\text {a }}$ Teresa (1997): La Novela Cómica, Madrid, CSIC, Literatura Breve 3.

Labrador, Julia M.a; del Castillo, Marie Christine y García Toraño, Covadonga (2005): La Novela de Hoy, La Novela de Noche y El Folletín Divertido. La labor editorial de Artemio
Precioso, Madrid, CSIC, Literatura Breve 15.

Magnien, Brigitte, et al. (1986): Ideología y texto en El Cuento Semanal, Madrid,

E. de la Torre.

Naval, M. Ángeles (2000): La Novela del Sábado y La Novela de Vértice, Madrid, CSIC, Literatura Breve 6.

Pérez Bowie, José Antonio (1996): La Novela Teatral, Madrid, CSIC, Literatura Breve 1.

Sánchez Álvarez-Insúa, Alberto (1996): Bibliografía e Historia de las Colecciones literarias en España (1907-1957), Madrid, Libris. 
- (1997): Las Colecciones Literarias en el Madrid de Alfonso XIII, Madrid, Ayuntamiento de Madrid-Instituto de Estudios Madrileños.

- (1997): La Novela Mundial, Madrid, CSIC, Literatura Breve 2 (con M. ${ }^{a}$ del Carmen Santamaría Barceló).

- (2001): Colecciones literarias en Historia de la Edición en España
(1836-1936), Jesús Martínez Martín (editor), Madrid, Marcial Pons, pp. 373-395.

- (2007): La colección literaria Los Contemporáneos, Monteagudo 12, Murcia, Universidad de Murcia, pp. 67-89.

- (2007): Las colecciones eróticas de Madrid y Barcelona. Dos maneras de entender la sexualidad. Cultura escri- ta et sociedad 5, Alcalá de Henares, pp. 140-156.

Santonja, Gonzalo (1979): La Novela Proletaria (1932-1933), Madrid, Ayuso.

- (1994): Las Novelas Rojas, Madrid, de la Torre.

Siguan Bohemer, Marisa (1981): Literatura popular libertaria. Trece años de La Novela Ideal (1925-1938), Barcelona, Península. 